Check for updates

Cite this: Phys. Chem. Chem. Phys., 2018, 20, 24033

Received 18th April 2018, Accepted 3rd September 2018

DOI: $10.1039 / \mathrm{c} 8 \mathrm{cp} 02463 d$

rsc.li/pccp

\section{Probing hydrogen bonding interactions and impurity intercalation in gibbsite using experimental and theoretical XANES spectroscopy $\dagger$}

\begin{abstract}
Grant J. Mclntosh (D) *ab and Andrew Chan (iD) ${ }^{b}$
The Al and O K-edge XANES spectra of Bayer process gibbsite are examined, both experimentally and with plane wave density functional theory, and transition assignments are made. We confirm that the broad transitions in Al K-edge spectra are fundamentally the same as those in more ordered and wellstudied corundum, and typical of octahedrally coordinated aluminium. Analysis of $\mathrm{O} \mathrm{K}$-edge spectra reveals that while much of the initial edge transition structure $(535-548 \mathrm{eV})$ is due to $\mathrm{O} 2 \mathrm{p}$ hybridization with $\mathrm{Al}$ orbitals, the lowest energy region $(\sim 535-539 \mathrm{eV})$ is particularly influenced by $\mathrm{O}-\mathrm{H}$ states which are heavily perturbed by hydrogen bonding interactions. We therefore tentatively suggest that an unexplained structure at $539 \mathrm{eV}$ in $\mathrm{O} \mathrm{K}$-edge spectra of corundum may be due to surface hydroxylation. Finally, we examined $\mathrm{Na} \mathrm{K}$-edge spectra, as sodium is the major impurity in these materials and implicated in perturbation of the evolution of materials properties with calcination through the transition aluminas. Density functional theory calculations find sodium replacement of in-sheet $\mathrm{H}$-atoms is the most thermodynamically stable site for sodium inclusion. We subsequently confirm this assignment spectroscopically, explicitly demonstrating the precise location of $\mathrm{Na}^{+}$impurities for the first time.
\end{abstract}

\section{Introduction}

Alumina is an extremely important industrial material, widely used in catalysis ${ }^{1-6}$ and adsorption. ${ }^{7-11}$ However, by far the largest consumer is the primary aluminium production industry that, in addition to using alumina as the primary feedstock, employs it as the dry scrubbing agent for hydrogen fluoride generated in the reduction cell. ${ }^{12-14}$ With many of alumina's applications crucially dependent on its surface chemistry, it is necessary to understand the evolution of these properties from the precursor to final product.

Calcination of gibbsite, $\mathrm{Al}(\mathrm{OH})_{3}$, or boehmite, $\mathrm{AlOOH}$, are the most common production routes for a variety of important alumina polymorphs. Although specific surface areas are low, both are also sorbents in their own right, ${ }^{15-18}$ and their surface chemistry is similarly of interest. Gibbsite and boehmite possess ordered crystal structures exhibiting sheets of octahedrally coordinated aluminium cations and weak inter-sheet bonding mediated

\footnotetext{
${ }^{a}$ Light Metals Research Centre, University of Auckland, Private Bag 92019, Auckland, New Zealand. E-mail: g.mcintosh@auckland.ac.nz

${ }^{b}$ School of Chemical Sciences, University of Auckland, Private Bag 92019, Auckland, New Zealand

$\dagger$ Electronic supplementary information (ESI) available: Corundum Al K-edge spectrum simulated without core-hole-inclusive pseudopotentials, and the $\mathrm{O} \mathrm{K}$ edge spectrum of carbon tape (background). See DOI: 10.1039/c8cp02463d
}

by hydrogen bonds (H-bonds) between hydroxyl moieties of opposing planes. Current mechanisms posit that the hydroxyls are progressively lost as $\mathrm{H}_{2} \mathrm{O}_{(\mathrm{g})}$ during calcination, with most of the inter-sheet regions collapsing and covalent $\mathrm{Al}-\mathrm{O}$ bonds forming in their place. ${ }^{19,20}$ As these transformations are pseudomorphic, ${ }^{21}$ volume losses are incorporated internally, leading to the cleaving of some of these sheets to ultimately become much of the internal porosity. The chemistry of alumina is thus arguably dominated by residual hydroxyl content and surface relaxation of these internal surfaces. $^{20}$

Understanding these processes is therefore important in controlling the properties and performance of alumina surfaces. $\mathrm{X}$-ray absorption near edge structure (XANES) spectroscopy is a powerful technique to probe surface chemistry and elementspecific local chemical environments. However, spectra can be extremely difficult to interpret. This is particularly true of transition aluminas as aluminium cations can be 4,5 , or 6-fold coordinated with considerable disorder in the occupancy of these sites, with occupancy also varying with phase. ${ }^{19,22-24}$ This in turn impacts interpretations of oxygen spectra, which are highly sensitive to the bonding interactions involved. ${ }^{25}$

Computational methods can be a powerful supplement in this regard. However, approaches require careful benchmarking before application to complicated systems such as the transition aluminas. Corundum and gibbsite are extremely 
attractive model systems for initial studies as they are single phase materials that exhibit cations with well-defined crystallographic locations, occupying octahedral sites exclusively. Additionally, these compounds exhibit only oxide or hydroxide interactions respectively.

A further complication stems from impurities. It has been demonstrated that sodium, the largest impurity in Bayer process aluminas, $^{26}$ can significantly impact surface chemistry, ${ }^{27-29}$ textural properties, ${ }^{30}$ and even phase transformation. ${ }^{31}$ Sodium is observed to surface segregate during calcination, ${ }^{31,32}$ consistent with DFT and experimental studies on sodium-doped $\gamma-\mathrm{Al}_{2} \mathrm{O}_{3}$ of Digne et $a l^{26}$ who demonstrated the energetic favourability of sodium in surface sites analogous to protons in hydroxyl groups, relative to bulk incorporation. It has considerable impacts on surface acidity, ${ }^{27,28}$ and thus the demand for sodium-free alumina drives the need for acid leaching procedures. $^{33}$

Understanding the location of sodium in precursor materials is important for understanding evolution with calcination and, given some observed commonalities with hydrogen ${ }^{26}$ may make sodium a useful proxy by which to study protons (invisible to $\mathrm{X}$-ray techniques such as XRD, XPS, and XAS). Indeed, Eremin et $a l^{34,35}$ argue for proton replacement by $\mathrm{Na}^{+}$as the primary intercalation mechanism during crystal growth. Lee et al. ${ }^{36}$ computationally confirm this exchange is energetically feasible. Comparison with lithium-intercalated gibbsite also suggests occupation of vacant octahedral sites is possible. ${ }^{37,38}$ Understanding sodium is also significant for technologically important materials. For example, $\beta$-sodium alumina, a solid electrolyte, relies on sodium ion migration through conduction planes consisting of loose-packed layers rich in sodium cations.

In this study we therefore consider Al, O, and Na K-edge XANES spectra of standard Bayer gibbsite samples. Being far more crystallographically ordered and less complicated than the wider class of transition aluminas, this material provides a convenient platform to benchmark core hole-inclusive pseudopotential methods to aid future experimental and theoretical studies of more complex and important classes of metal oxides and doped metal oxides.

\section{Methods}

\subsection{Experimental methodology}

Bayer gibbsite was sourced from a large commercial alumina refinery whose identity is confidential (although is expected to be a representative material), and used as received. Pure corundum, -100 mesh, was purchased from Sigma-Aldrich. $\mathrm{X}$-ray absorption near edge structure (XANES) spectroscopy was performed on the Soft X-ray (SXR) beamline at the Australian Synchrotron. ${ }^{39}$ The storage ring was operated at $3 \mathrm{GeV}$ to provide a photon flux of $\sim 5 \times 10^{11} \mathrm{~s}^{-1} 200 \mathrm{~mA}$ for the duration of the experiments. Powdered alumina samples were mounted onto drain current holders using carbon tape then introduced into UHV conditions $\left(\sim 8 \times 10^{-10} \mathrm{mbar}\right)$. Monochromated and elliptically polarized soft X-rays produced from an undulator insertion device were focussed to a $0.2 \times 0.5 \mathrm{~mm}$ spot using a double crystal monochromator. Partial electron yield (PEY) and total fluorescence yield (TFY) measurements were optimized using a channeltron electron multiplier and multichannel plate, respectively. All XANES data were processed using the QANT Igor macro (version 1.9, 2017) developed by Gann et al. ${ }^{40}$ All spectra were collected using a flood gun to compensate for sample charging then normalised against the $I_{0}$ current measured simultaneously on a gold mesh. Photon energy calibration was performed over the $\mathrm{Al}, \mathrm{O}$, and $\mathrm{Na}$ K-edges using signals from $\mathrm{Al}$ foil, $\mathrm{MnO}$ and $\mathrm{NaCl}$ powder reference materials, respectively, measured concurrently to account for photon energy drift. Spectra were recorded in a single scan with stepsizes of $0.17 \mathrm{eV}, 0.10 \mathrm{eV}$, and $0.10 \mathrm{eV}$ for $\mathrm{Al}, \mathrm{Na}$ and $\mathrm{O}$ K-edges respectively, and at a scan rate of $0.5 \mathrm{~s}$ per step. Finally, all spectra are normalized as per convention (pre-edge baseline set to zero, post-edge to 1 ).

\subsection{Computational methodology}

All XANES spectra were computed with the XSPECTRA code $e^{41,42}$ This package computes the X-ray absorption cross-section by evaluating Fermi's golden rule:

$$
\sigma(\omega)=4 \pi^{2} \alpha \hbar \omega_{\mathrm{i}} \sum_{\mathrm{f}}|\langle\mathrm{f}|D| \mathrm{i}\rangle|^{2} \delta\left(\hbar \omega_{\mathrm{i}}-E_{\mathrm{i}}-E_{\mathrm{f}}\right)
$$

where $\hbar \omega_{\mathrm{i}}$ is the energy of the incident X-ray energy, $|\mathbf{i}\rangle$ and $|\mathbf{f}\rangle$ the initial and final states, respectively, with $E_{\mathrm{i}}$ and $E_{\mathrm{f}}$ their respective energy eigenvalues, and $D$ the operator coupling the system to the X-ray field. This is evaluated in the dipole approximation. In evaluating eqn (1) within the XSPECTRA package, the all-electron wavefunction $|\psi\rangle$ is constructed using the projector augmented wave (PAW) method $^{43}$ from the pseudowave function $|\tilde{\psi}\rangle$ by the linear operator $T$ :

$$
|\psi\rangle=T|\tilde{\psi}\rangle
$$

This operator is expressed in terms of projector functions $\left\langle\tilde{p}_{\mathbf{R}, n}\right|$ and all-electron and pseudo- partial waves $\left\langle\tilde{\varphi}_{\mathbf{R}, n}\right|$ and $\left\langle\varphi_{\mathbf{R}, n}\right|$, respectively:

$$
T=1+\sum_{\mathbf{R}, n}\left(\left|\varphi_{\mathbf{R}, n}\right\rangle-\left|\tilde{\varphi}_{\mathbf{R}, n}\right\rangle\right)\left\langle\tilde{p}_{\mathbf{R}, n}\right|
$$

These functions are centred around atomic sites $\mathbf{R}$. The partial pseudowave centred on the absorber atom $\mathbf{R}_{0}$ can be shown $^{41,42}$ to be:

$$
\left|\tilde{\varphi}_{\mathbf{R}_{0}}\right\rangle=\sum_{n}\left|\tilde{p}_{\mathbf{R}_{0}, n}\right\rangle\left\langle\varphi_{\mathbf{R}_{0}, n}|D| \mathrm{i}\right\rangle
$$

And the absorption cross-section subsequently:

$$
\sigma(\omega)=4 \pi^{2} \alpha \hbar \omega_{\mathrm{i}} \sum_{\mathrm{f}}\left|\left\langle\tilde{\psi}_{\mathrm{f}} \mid \tilde{\varphi}_{\mathbf{R}_{0}}\right\rangle\right|^{2} \delta\left(\hbar \omega_{\mathrm{i}}-E_{\mathrm{i}}-E_{\mathrm{f}}\right)
$$

Gougoussis et al. ${ }^{42}$ then introduce the $S$ operator with a view to evaluating eqn (1) within the ultrasoft pseudopotential scheme: ${ }^{44}$

$$
S=1+\sum_{\mathbf{R}, m, n}\left|\tilde{p}_{\mathbf{R}_{0}, n}\right\rangle\left(\left\langle\varphi_{\mathbf{R}, n}|D| \varphi_{\mathbf{R}, m}\right\rangle-\left\langle\tilde{\varphi}_{\mathbf{R}, n}|D| \tilde{\varphi}_{\mathbf{R}, m}\right\rangle\right)\left\langle\tilde{p}_{\mathbf{R}, m}\right|
$$

and, by also introducing the pseudo-Hamiltonian $\tilde{H}$

$$
\tilde{H}|\psi\rangle=\mathrm{ES}|\psi\rangle
$$


a Green's function operator $\tilde{G}(x)$ (for real $x$ ) can be defined:

$$
\tilde{G}(x)=S^{-1 / 2} \frac{1}{x-S^{-1 / 2} \tilde{H} S^{-1 / 2}-\mathrm{i} \gamma} S^{-1 / 2}
$$

Finally, it has been shown ${ }^{42}$ that combining eqn (1), (4), and (8) leads to:

$$
\sigma(\omega)=4 \pi \alpha \hbar \omega_{\mathrm{i}} \lim _{\gamma \rightarrow 0} \operatorname{tr}\left[\left\langle\tilde{\varphi}_{\mathbf{R}_{0}}\left|\tilde{G}\left(\hbar \omega_{\mathrm{i}}-E_{\mathrm{i}}\right)\right| \tilde{\varphi}_{\mathbf{R}_{0}}\right\rangle\right]
$$

The matrix element is evaluated with the Lanczos recursion method. ${ }^{45}$ This method therefore allows the absorption cross-section to be evaluated practically from conventional DFT-based band structure calculations, using ultrasoft pseudopotentials. This alleviates problems with popular multiple scattering-based alternatives where a cluster size around the absorber must specified while also avoiding the muffin-tin approximation. ${ }^{46}$ However, it does require care in choosing unit cell sizes and particularly large supercells are usually required, thereby demanding more computational resources. Generally, it also requires the use of pseudopotentials explicitly incorporating a core hole. These require explicit benchmarking, and indeed this is one of the primary aims of this work.

Eqn (5) helps to highlight the connection between absorption cross-section and the overlap of states computed with pseudopotentials, and therefore interpretation of XANES peaks as electronic transitions. This interpretation has become less popular relative to multiple scattering paradigms which lead more naturally to the interpretation of all peaks as scattering events associated with the outgoing photoelectron wave. Eqn (9) demonstrates that this view is also encapsulated in treatment by the XSPECTRA package with $\tilde{G}(x)$ the propagator of the electron wave (evaluated within the framework of DFT calculations with ultrasoft pseudopotentials). However, much emphasis will still be placed in this work on the conceptual framework that views the absorption cross-section as the result of core electron excitation into the valence band as this approach is still widely used by experimentalists to interpret the spectra of metallic cations in particular. ${ }^{47-50}$ In such cases, interpretation based on crystal field theory is very common. As such, we will make extensive use of projected density of states (pDOS) in order to make closer connection to the prior experimental assignments.

First-principles calculations, including SCF calculations, geometry optimizations, and simulated XANES spectra were undertaken by plane-wave density functional theory using the PBE approximation ${ }^{51}$ with the QUANTUM-ESPRESSO suite of codes. $^{52,53}$ Troullier-Martins norm-conserving pseudopotentials were generated for $\mathrm{Al}$ and $\mathrm{Na}$ with $3 \mathrm{~s}, 3 \mathrm{p}$, and $3 \mathrm{~d}$ valence orbitals; the $3 \mathrm{~s}$ occupancy of sodium was set to 0.5 to account for its tendency toward ionisation. Oxygen was generated with $2 \mathrm{~s}, 2 \mathrm{p}$ and $3 \mathrm{~d}$ valence orbitals. Pseudopotentials of all absorbing atoms in XANES calculations were generated analogously using the ATOMIC code, but include core-hole effects simulated by restricting the occupancy of $1 \mathrm{~s}$ orbitals to a single electron.
The $\mathrm{Al}$ and $\mathrm{O}$ K-edge spectra for corundum and the $\mathrm{Na}$ K-edge spectrum of $\mathrm{NaCl}$ were simulated in order to benchmark our pseudopotentials. Locations of $\mathrm{Al}^{3+}$ and $\mathrm{O}^{2-}$ in corundum $(R \overline{3} c)$ were read from PDF-card 46-1212, and used to construct $2 \times 2 \times 2$ supercells (240 atoms) without further optimization. The PDF-card 83-1728 was employed to determine the location of $\mathrm{Na}^{+}$and $\mathrm{Cl}^{-}$in $\mathrm{NaCl}(\mathrm{Fm} \overline{3} \mathrm{~m})$ from which a $3 \times 3 \times 3$ supercell (216 atoms) was constructed and also used without further optimization. The large cells were required to keep absorbing centres in neighbouring periodic images sufficiently distant during XANES simulations as to be effectively non-interacting.

Sodium-containing gibbsite, on the other hand, does not possess a known structure and geometries were necessarily constructed computationally. Initial geometries were taken from PDF-card 70-2038 for pure gibbsite. Pre-optimized dimensions of the 448 atom $(2 \times 2 \times 2)$ supercell $\left(P 12_{1} / n 1\right)$ are $a=17.368 \AA, b=10.156 \AA$, and $c=19.472 \AA$, with $\alpha=90.0^{\circ}$, $\beta=94.54^{\circ}$, and $\gamma=90.0^{\circ}$. Appropriate replacements of protons by sodium were made, with geometry optimizations then performed with the PWscf code on the supercells using a $(1 \times 1 \times 1) k$-point grid, a plane wave energy cutoff of $45 \mathrm{Ry}$, and a density cutoff of 540 Ry. Full cell optimization was performed with symmetry ignored.

For XANES simulations the final geometries were subjected to SCF energy calculation on a $(3 \times 3 \times 3) k$-point grid, a plane wave energy cutoff of $80 \mathrm{Ry}$, and a density cutoff of $960 \mathrm{Ry}$. XANES spectra were computed from $-10 \mathrm{eV}$ to $50 \mathrm{eV}$, where the Fermi level is set to zero energy, over a $(4 \times 4 \times 4) k$-point grid. Broadening parameters for transitions were chosen to best qualitatively match experimental spectra as discussed below. The energy scales of the simulated spectra were offset by a constant value chosen in order to achieve the closest match with experiment.

\section{Results and discussion}

\subsection{Benchmarking Al, $\mathrm{O}$, and Na K-edge XANES spectra}

Al K-edge spectra of corundum have been simulated previously with extremely good agreement with experiment. ${ }^{54-57}$ Our spectra similarly show very good agreement with experiment (Fig. 1) which are also consistent with previous measured spectra. ${ }^{58-60}$ All features $A-G_{2}$ up to $\sim 22 \mathrm{eV}$ above the edge are reproduced with the exception of the pre-edge feature $p$. Calculations repeated without including a core-hole in the absorber pseudopotential (Fig. S1, ESI $\dagger$ ) demonstrate very poor agreement, indicating that these cannot be neglected. The pre-edge is attributed to a weak transition that arises as a consequence of symmetry-breaking, ${ }^{20}$ either due to distortion inherent in the $\mathrm{AlO}_{6}$ units or vibrational motion. ${ }^{57}$ The pDOS calculations confirm previous assignments describing $\mathrm{p}$ as a dipole-forbidden $1 \mathrm{~s} \rightarrow 3 \mathrm{~s}$ excitation in the absorber $\mathrm{Al}$ atom $\mathrm{Al}^{*},{ }^{57,58}$ as understood within the crystal field theory/electronic excitation paradigm. ${ }^{61}$ We do not find evidence of $\mathrm{p}$ being a consequence of the hybridisation of $\mathrm{Al} \mathrm{p}$ and $\mathrm{O} \mathrm{p}$ orbitals as suggested following the multiple scattering calculations of 


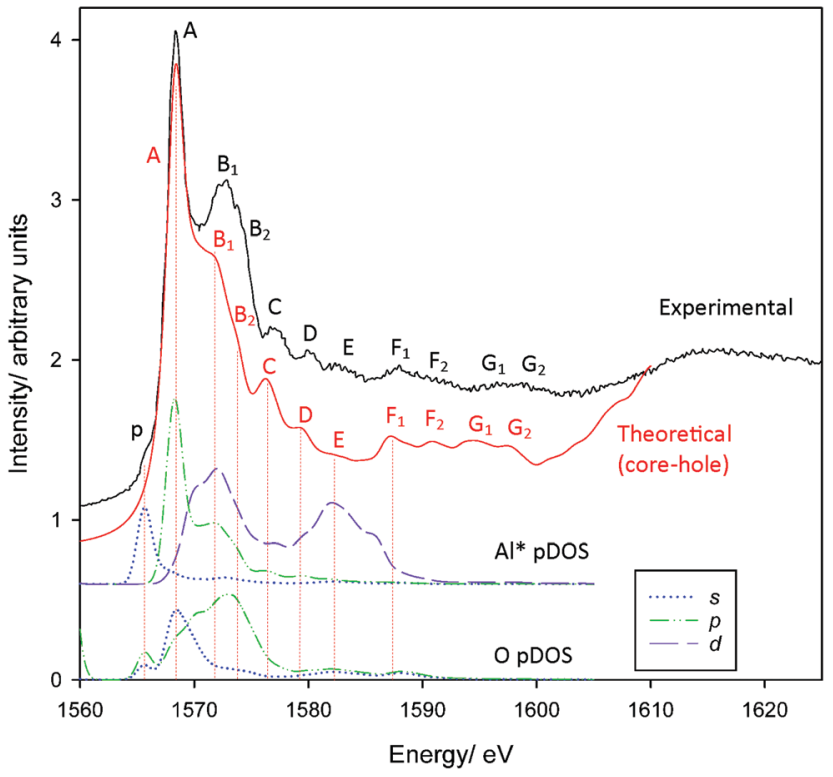

Fig. 1 Measured and calculated PEY Al K-edge XANES spectra of corundum. Also provided are $\mathrm{Al}^{*} 3 \mathrm{~s}, 3 \mathrm{p}, 3 \mathrm{~d}$ and $\mathrm{O} 2 \mathrm{~s}, 2 \mathrm{p}$ pDOS results.

Mottana et al., ${ }^{60}$ although the transition may indeed involve some $\mathrm{O} 2 \mathrm{p}$ contribution.

Other peaks also agree broadly with the assignments of $\mathrm{Li}$ et $a l^{58}$ Incidentally, these assignments are consistent with changes in intensity following changes in selection rules when examining $\mathrm{L}_{2,3}$-edge spectra ${ }^{62-64}$ Peak A coincides with an $\mathrm{Al}^{*}$ $3 p$ band consistent with previous assignment as a Laporteallowed $\mathrm{a}_{1 \mathrm{~g}}(1 \mathrm{~s}) \rightarrow \mathrm{t}_{1 \mathrm{u}}(3 \mathrm{p}$-like) transition. However, we find here that the $3 \mathrm{p}$-band is split on interaction with neighbouring $\mathrm{O}$-atoms, and peak $\mathrm{A}$ is perhaps more appropriately considered a transition into $\mathrm{Al}^{*}(3 \mathrm{p})-\mathrm{O}(2 \mathrm{~s})$ hybrid states. The second mixed state, $\mathrm{Al}^{*}(3 \mathrm{p})-\mathrm{O}(2 \mathrm{p})$, coincides with peaks $\mathrm{B}_{1} / \mathrm{B}_{2}$ as does an $\mathrm{Al}^{*}(3 \mathrm{~d})$ band. We find the $3 \mathrm{~d}$ states are broadly split into two groups, consistent with $t_{2 g}-e_{g}$ splitting predicted with crystal field theory. Experimental assignments describe peaks $B_{1} / B_{2}$ as an $\mathrm{Al}^{*}$-centred $\mathrm{a}_{1 \mathrm{~g}}(1 \mathrm{~s}) \rightarrow \mathrm{t}_{2 \mathrm{~g}}\left(3 \mathrm{~d}\right.$-like) transition..$^{58}$ In a strict $O_{\mathrm{h}}$ environment this transition should be Laporte-forbidden. Local symmetry breaking and hybridisation could relax these rules sufficiently to describe the observed intensity, however, it may also be reasonable to re-assign these transitions as primarily $\mathrm{Al}^{*}(3 \mathrm{p})$-like, or a mixture of both. We will return to this point shortly.

The influence of $\mathrm{Al}^{*}(3 \mathrm{p})$ orbitals or mixing with adjacent (ligand) orbitals is supported by the low intensity of peak E. This is assigned as an $\mathrm{a}_{1 \mathrm{~g}}(1 \mathrm{~s}) \rightarrow \mathrm{e}_{\mathrm{g}}\left(3 \mathrm{~d}\right.$-like) transition, ${ }^{58}$ which is also strictly forbidden, and our pDOS calculations confirm a coincidence with $\mathrm{Al}^{*} 3 \mathrm{~d}$-bands. The low intensity of peak $\mathrm{E}$ suggests that symmetry breaking alone is insufficient to allow the $\mathrm{t}_{2 \mathrm{~g}}$ (3d-like) bands to contribute to peaks $\mathrm{B}_{1} / \mathrm{B}_{2}$. Overlap with orbitals predominantly from adjacent atoms is required for $\mathrm{Al}^{*}(3 \mathrm{~d})$ states to contribute to peaks $\mathrm{B}_{1} / \mathrm{B}_{2}$.

Finally, peak $\mathrm{D}$ is assigned as a multiple scattering event. ${ }^{58}$ While all transitions can be interpreted as multiple scattering

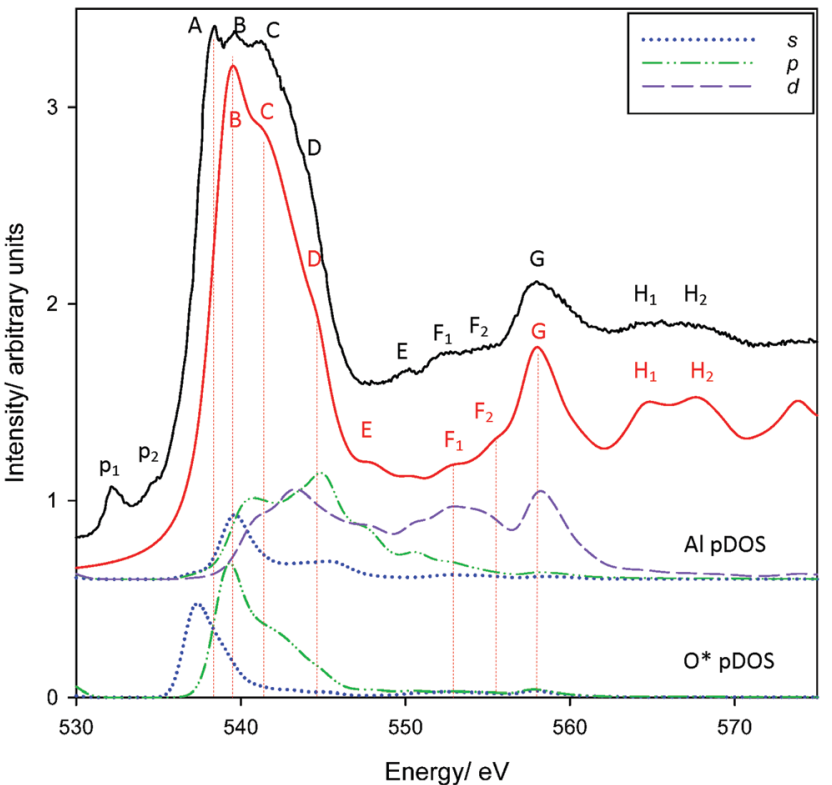

Fig. 2 Measured and calculated PEY $O$ K-edge XANES spectra of corundum. Also provided are $\mathrm{Al}^{\star} 3 \mathrm{~s}, 3 \mathrm{p}, 3 \mathrm{~d}$ and $\mathrm{O} 2 \mathrm{~s}, 2 \mathrm{p}$ pDOS results.

events, we confirm this assignment is reasonable insofar as there are no clear coincidences with the local band structure that would otherwise provide a definable electronic transition.

$\mathrm{O}$ K-edge spectra for corundum are reproduced in Fig. 2. Overall, there is extremely good agreement in features $\mathrm{B}-\mathrm{H}_{2}$. As with the Al K-edge, pre-edge features $\mathrm{p}_{1}$ and $\mathrm{p}_{2}$ were not reproduced. However, $\mathrm{p}_{1}$ and $\mathrm{p}_{2}$ are present in the carbon tape substrate $^{20}$ (see Fig. S2, ESI $\dagger$ ) and are most likely either epoxide transitions or, less likely, defects/vacancies from beam damage ${ }^{25}$ or oxygen scavenging. ${ }^{65}$

Most importantly, one of the primary edge features (A) is not reproduced. Experimental spectra show three distinct peaks, $\mathrm{A}-\mathrm{C}$, with a shoulder $\mathrm{D}$. The theoretical spectrum shows three peaks, tentatively ascribed as peaks B-D although this is ambiguous. However, shifting the theoretical spectrum $\sim 2 \mathrm{eV}$ lower (equivalent to assigning these bands as A-C) shows an overall poorer agreement with experiment, resulting in less consistency in the intensities of assigned features and worse agreement in the transition energies of peaks $\mathrm{E}-\mathrm{H}_{2}$. The possible origin of the unexplained peak A will be considered shortly. The scaled spectrum of the carbon tape background (Fig. S2, ESI $\dagger$ ) makes it is clear that the pre-edge features $\mathrm{p}_{1}$ and $\mathrm{p}_{2}$ are artefacts and will not contribute appreciably to the spectrum of corundum. The inclusion of $\mathrm{Al}$ and $\mathrm{O}$ pDOS demonstrate that the edge is predominantly excitation into the $\mathrm{O}^{*}(2 \mathrm{p})$ valence band, which in turn coincide with features in the $3 \mathrm{~s}, 3 \mathrm{p}$, and $3 \mathrm{~d}$ pDOS from directly-bonded $\mathrm{Al}$ atoms. This agrees with prior experiments that argue that the $\mathrm{O}$ K-edge is largely due to excitation of $\mathrm{O} 1 \mathrm{~s}$ electrons into unoccupied $\mathrm{O} 2 \mathrm{p}$ states hybridized with the orbitals of the bonding atom. ${ }^{20,25,64-67}$ Our pDOS calculations provide some further detail, indicating that peak B is largely $\mathrm{O}^{*}(2 \mathrm{~s})-\mathrm{Al}(3 \mathrm{~s})$, peak $\mathrm{D}$ arguably $\mathrm{O}^{*}(2 \mathrm{~s})$ $\mathrm{Al}(3 \mathrm{~d})$, although peak $\mathrm{C}$ may be a complicated mixture with $\mathrm{Al} 3 \mathrm{p}$ 


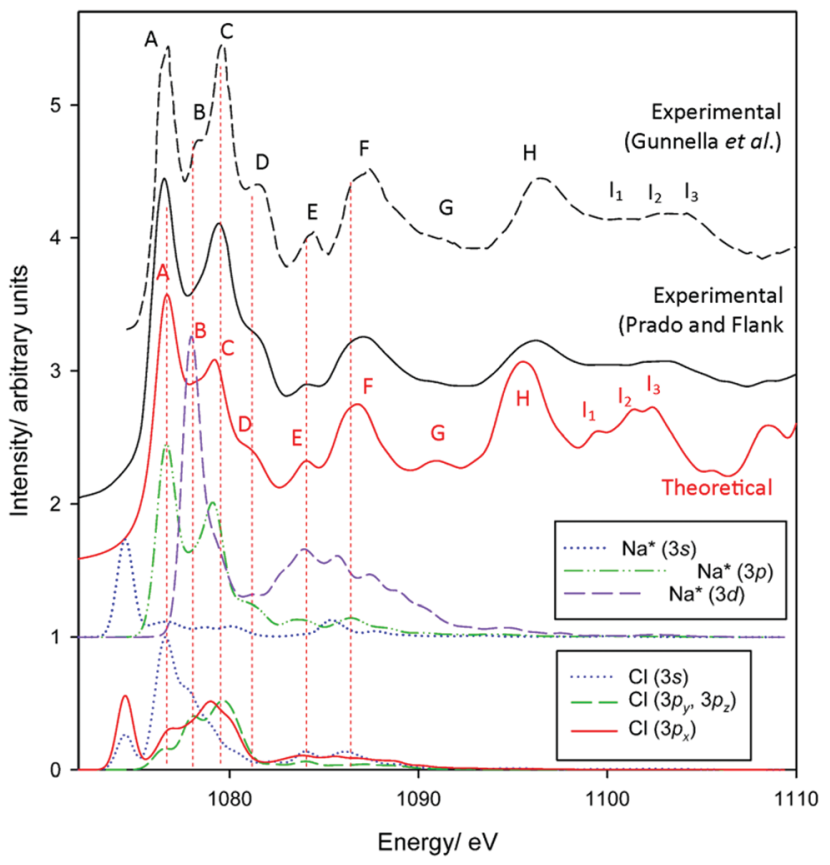

Fig. 3 Measured and calculated Na K-edge XANES spectra of sodium chloride. Experimental data have been reproduced from Gunnella et al. ${ }^{68}$ and Prado and Flank. ${ }^{69}$

and 3d states. However, no bands match peak A. This is therefore either due to a physical process not modelled with XSPECTRA, or is the consequence of a missing feature in our chosen supercell.

Finally, to benchmark Na K-edge spectra, experimental and simulated spectra for $\mathrm{NaCl}$ are provided in Fig. 3. As with the theoretical Al and O K-edge spectra, peaks $\sim 20-30 \mathrm{eV}$ above the absorption edge tend to be a little more intense than their experimental counterparts. Otherwise, intensity and transition energies are in extremely good agreement. We identify 11 modes up to $\sim 25 \mathrm{eV}$ above the absorption edge in the experimental spectra, with all reproduced in the modelled spectrum. Theory underestimates experimental energies very slightly, generally by at most $0.5 \mathrm{eV}$, in the labelled peaks. The pDOS calculations are again often consistent with crystal field splitting considerations. The pre-edge represents a $\mathrm{a}_{1 g}(1 \mathrm{~s}) \rightarrow \mathrm{a}_{1 \mathrm{~g}}(3 \mathrm{~s})$ transition, again strictly forbidden in pure octahedral environments. However, a deviation from theory occurs with the strong edge features $\mathrm{A}$ and $\mathrm{C}$, which we find are transitions into states of almost exclusively $\mathrm{Na}(3 \mathrm{p})$ character. The otherwise triply degenerate $\mathrm{Na}(3 \mathrm{p})$ states of $\mathrm{t}_{2 \mathrm{~g}}$-symmetry, as understood through crystal field theory, are split on interaction with $\mathrm{Cl} 3 \mathrm{~s}$ and $3 p$ states, as seen between $\mathrm{Al}^{3+}$ and $\mathrm{O}^{2-}$ in corundum.

The $\mathrm{Na}(3 \mathrm{~d})$ state is also split into two distinct bands consistent with $t_{2 g}$ and $e_{g}$ states. Excitation into the Laporteforbidden $t_{2 g}$-like state shows a strong correspondence with peak B. This feature, somewhat observed experimentally, is observed most prominently in the measurements of Gunnella et $a l .{ }^{68}$ This also coincides with bands in the $\mathrm{Cl}$ valence states, particularly in the $3 \mathrm{~s}$ band. Given the highly symmetric environment in $\mathrm{NaCl}$, this indicates that $\mathrm{t}_{2 \mathrm{~g}}$-transitions do indeed exhibit non-zero intensity due to overlap with adjacent orbitals. This argues therefore that the $\mathrm{B}_{1} / \mathrm{B}_{2}$ peaks in the $\mathrm{Al} \mathrm{K}$-edge spectrum of corundum represent both split $t_{1 u}(3 p$-like $)$ and $\mathrm{t}_{2 \mathrm{~g}}$ (3d-like) transitions.

Peak D corresponds to transitions into a largely pure $\mathrm{Na}(3 \mathrm{p})$ state. Features $\mathrm{E}$ and $\mathrm{F}$ may also represent transitions into $\mathrm{Na}(3 \mathrm{p})$ states, now interacting with $\mathrm{Cl} 3 \mathrm{~s}$ orbitals, and may also exhibit some contributions from $e_{g}\left(\mathrm{Na}^{*} 3 \mathrm{~d}\right.$-like $)$ bands, although the latter again should be dipole forbidden.

\subsection{Geometry optimization of sodium-doped gibbsite.}

Before performing similar analyses on less-studied gibbsite, we must first locate the most thermodynamically stable crystallographic position for $\mathrm{Na}^{+}$in a gibbsite matrix. In pure gibbsite, two broadly distinct sets of protons are observable (Fig. 4 left). These run either parallel to the $c$-axis, bonding $\mathrm{AlO}_{6}$ sheets together, or within the $a b$-plane. We refer to the former environment as inter-sheet, and the latter in-plane. The $\mathrm{AlO}_{6}$ sheets also possess a number of octahedral cation vacancies (Fig. 4 right). All are potential sites for sodium inclusion or intercalation.

Replacing one proton of each class with $\mathrm{Na}^{+}$leads to two sodium-substituted models, each necessarily losing symmetry as a consequence of substitution (Fig. 5). Geometric parameters after full cell optimization (Table 1) reveal little difference in the overall dimensions between the two structures or with those crystallographically determined for pure gibbsite. The in-plane sodium conformation is found to be $25.0 \mathrm{~kJ} \mathrm{~mol}^{-1}(0.259 \mathrm{eV})$ lower in energy than the inter-sheet structure. Therefore, if sodium intercalation does occur by way of proton replacement, it should be overwhelmingly present in the in-plane conformation. This agrees with the findings of the computational study of Lee et al. ${ }^{36}$

A third stable intercalation mode is found in which sodium occupies an octahedral cation vacancy (Fig. 5 right). To conserve
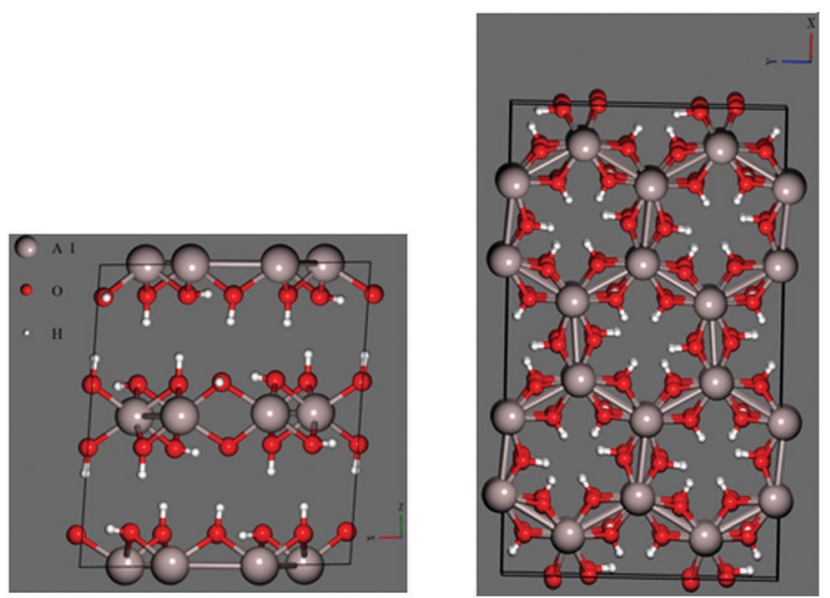

Fig. 4 Unoptimized gibbsite $(1 \times 1 \times 1)$ cell highlighting (left) the two distinctive $\mathrm{H}$-bonding environments: vertical (parallel to the $c$-axis) are inter-sheet, and horizontal (in the ab-plane) in-plane. Octahedral cation vacancies are also present in these sheets; these are in the centres of the hexagonal aluminium motifs observable when looking down the $c$ axis (right). 

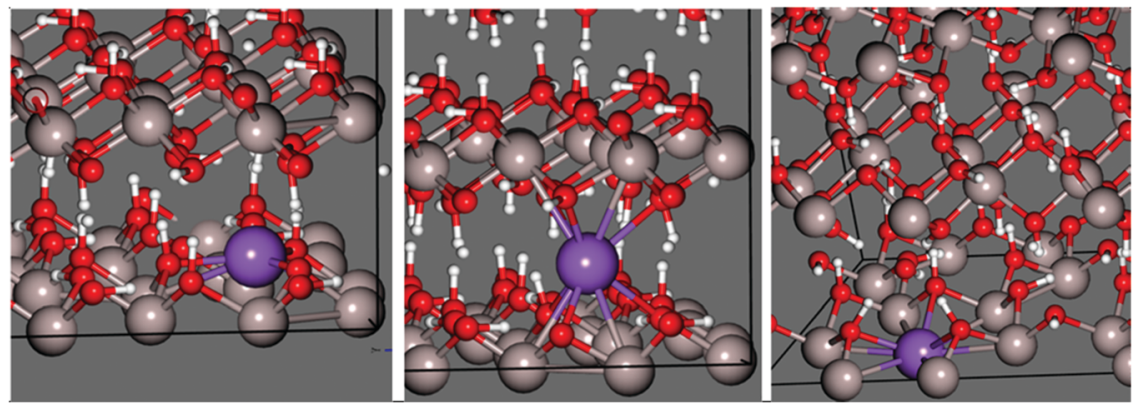

Fig. 5 Optimized Na-doped gibbsite $(2 \times 2 \times 2)$ supercells demonstrating the (left) in-plane and (centre) energetically unfavourable inter-sheet sodiumreplacement intercalation environments. A stable octahedral vacancy environment, with an additional stabilizing $\mathrm{OH}$ in the inter-sheet region, is also located (right).

Table 1 Cell dimensions of Na-doped gibbsite $(2 \times 2 \times 2)$ supercells determined by plane wave DFT

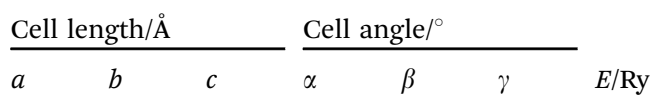

Measured $17.368 \quad 10.156 \quad 19.472 \quad 90.000 \quad 94.540 \quad 90.000 \quad$ n.a. $\begin{array}{lllllllll}\text { Inter-sheet } & 17.482 & 10.224 & 19.456 & 90.083 & 92.748 & 89.919 & -6889.657\end{array}$ $\begin{array}{lllllllll}\text { In-plane } & 17.519 & 10.232 & 19.375 & 90.042 & 92.803 & 89.958 & -6889.676\end{array}$ $\begin{array}{llllllll}\text { Octahedral } & 17.596 & 10.256 & 19.522 & 90.153 & 92.256 & 89.806 & -6924.413\end{array}$

charge, an $\mathrm{OH}^{-}$counter-ion is initially placed in the inter-sheet region, modelled after the observed structure of lithium intercalated compounds. ${ }^{37,38}$ This means, however, that the energy of this structure cannot be directly compared with the hydrogen substitution models.

These structures differ considerably in terms of local coordination. Coordination polyhedra and their geometries are shown $^{70}$ in Fig. 6. Inter-sheet sodium is located in the centre of a distorted trigonal prismatic oxygen polyhedron (bond lengths vary from 2.12-2.43 $\AA$ ) with an effective coordination of 5.12. In-plane sodium, on the other hand, sits on the face, or just above the centre, of octahedral cation vacancy polyhedron, in the plane of the hydroxyl groups. It is primarily in a threecoordinate trigonal planar structure (in the face of the octahedron) with shorter $\mathrm{Na}-\mathrm{O}$ distances of 2.08-2.15 ̊. This is supported by an effective coordination number of 3.23 . Deviations from 3.00 are due to more distant interactions (2.57-2.80 $)$ with two additional oxygen atoms present in the underside of the Al-rich sheet, and is therefore quasi-five-fold coordinated. With its near-association with the octahedral vacancy, this environment could also be considered a highly distorted octahedral coordination.

In the explicitly octahedral environment itself, sodium recesses into the vacancy (in-plane with aluminium cations). However, the migration of the hydroxyl counter-ion during optimization ultimately results in an almost 7-fold coordination, although the effective coordination number of 5.65 reflects the long $\mathrm{Na}^{+}-\mathrm{OH}^{-}$bond length $\left(2.73 \AA\right.$ A). This close $\mathrm{Na}^{+}-\mathrm{OH}^{-}$proximity will be the lowest energy arrangement as the charges stabilize one another electrostatically.
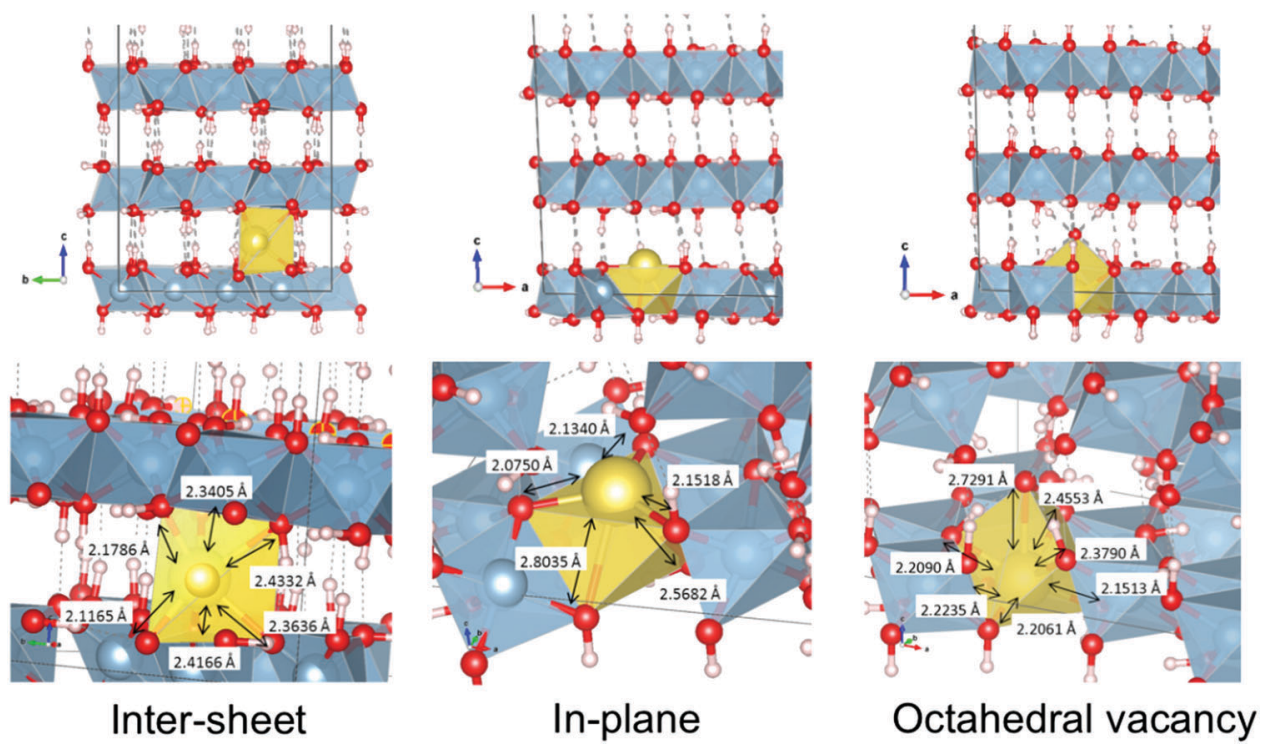

Fig. 6 Geometries and coordination polyhedra of optimized intercalated sodium environments in gibbsite. 


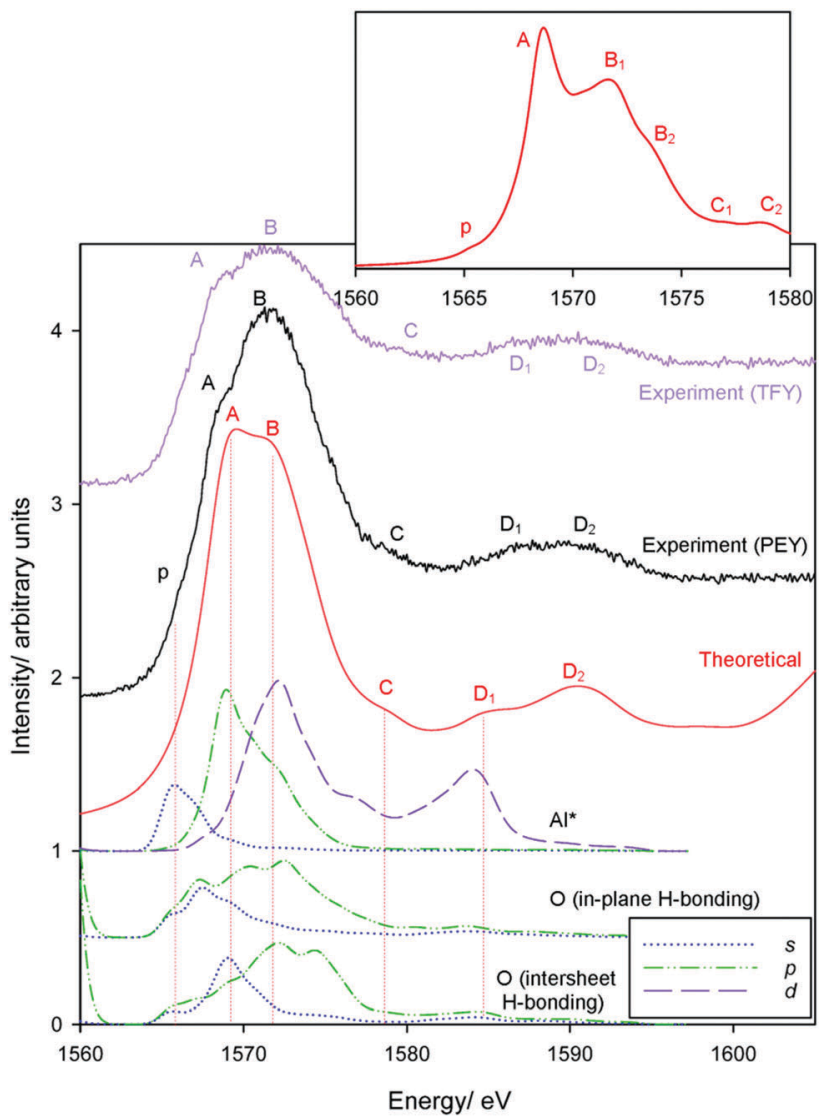

Fig. 7 Al K-edge spectra of gibbsite recorded in both PEY and TFY modes. Theoretical spectra are computed with $1.5 \mathrm{eV}$ broadening factors, with a magnified view of the absorption edge computed with a $0.6 \mathrm{eV}$ broadening factor.

Analogously, coordination of lithium by chloride counterions is found in gibbsite intercalation compounds with $\mathrm{Li}-\mathrm{Cl}$ distances measured to be $3.75 \AA{ }^{37}$ Average bond lengths are very similar, 2.31, 2.35, and $2.34 \AA$ for inter-sheet, in-plane, and octahedral coordination respectively. However, the very different geometries should make the structures easy to differentiate in XANES spectroscopy.

\subsection{Al K-edge spectra of gibbsite}

Local $\mathrm{Al}^{3+}$ geometries in gibbsite are, as in corundum, exclusively octahedral. Consequently, both compounds should exhibit very similar transitions. Local $\mathrm{Al}^{3+}$ environments are more disordered in gibbsite, ${ }^{59,71}$ broadening XANES transitions and obscuring similarities. Experimental spectra in both PEY and
TFY modes are given in Fig. 7, and agree with previous measurements. ${ }^{72}$ Theory matches experiment very well, with all features of the PEY and TFY spectra modelled; a constant broadening term of $1.5 \mathrm{eV}$ (compare with $0.6 \mathrm{eV}$ with corundum) was employed to account for greater local disorder.

The barely resolved measured pre-edge feature $\mathrm{p}$ at $1566 \mathrm{eV}$ appears poorly described by theory, but is well described when applying a narrower broadening factor ( $0.6 \mathrm{eV}$ - Fig. 7 inset). Measured transitions A-D are all very well described, with theory helping to highlight transition $\mathrm{C}$ that is otherwise difficult to discern experimentally.

Theoretically narrowing peaks beyond that achievable experimentally (Fig. 7 inset) highlights the close correspondence between $\mathrm{Al}$ absorption features in corundum (Fig. 1) and gibbsite. For example, peak B splits into two transitions in gibbsite, also seen in corundum. This correspondence indicates that band assignments of $\mathrm{Li}$ et $a l .{ }^{58}$ for corundum may be directly applicable to gibbsite - see Table 2 . The $\mathrm{Al}^{*}(3 \mathrm{~s})$ band maximum coincides with peak $\mathrm{p}$, again indicating a symmetry forbidden $\mathrm{a}_{1 \mathrm{~g}}(1 \mathrm{~s}) \rightarrow \mathrm{a}_{1 \mathrm{~g}}(3 \mathrm{~s})$ transition for octahedrally coordinated $\mathrm{Al}^{3+}$. The strong edge transition (peak $\mathrm{A}$ ) at $1568.5 \mathrm{eV}$ is primarily $\mathrm{Al}(3 \mathrm{p})$ in nature, but (as with corundum and $\mathrm{NaCl})$ exhibits coincidence with $\mathrm{O}(2 \mathrm{~s})$ bands. In this system, we recognise each hydroxyl group and the associated O-atom may exist in differing environments particularly depending on whether it participates in in-plane or intersheet H-bonding. As also seen in corundum, the $\mathrm{Al}^{*}(3 \mathrm{p})$ states mix to form $\mathrm{Al}^{*}(3 \mathrm{p})-\mathrm{O}(2 \mathrm{~s})$ and $\mathrm{Al}^{*}(3 \mathrm{p})-\mathrm{O}(2 \mathrm{p})$ bands, the latter coinciding with both peak $B$ and a $t_{2 g}$ (3d-like) band. The narrower bands in Fig. 7 (inset) suggests an additional peak between $\mathrm{A}$ and $\mathrm{B}_{1}$, arguing that the resonances between $\sim 1570-1575 \mathrm{eV}$ are a consequence of both $\mathrm{Al}^{*}(3 \mathrm{p})-\mathrm{O}(2 \mathrm{p})$ and $\mathrm{t}_{2 \mathrm{~g}}\left(\mathrm{Al}^{*} 3 \mathrm{~d}\right.$-like) transitions.

Peak C $(1578 \mathrm{eV})$ does not show a strong correlation with electronic states. This again suggests a lack of a well-defined electronic transition, consistent with prior experimental assignments as 'multiple scattering events'. Peak $\mathrm{D}_{1}$ has some $\mathrm{Al}^{*}(3 \mathrm{~d})$ character, consistent with an $\mathrm{e}_{\mathrm{g}}\left(\mathrm{Al}^{*} 3 \mathrm{~d}\right.$-like) band. However, this is not the primary contribution to the $D_{1} / D_{2}$ peaks, which similarly lack a clear correspondence with electronic transitions, and noting the $\mathrm{a}_{1 \mathrm{~g}} \rightarrow \mathrm{e}_{\mathrm{g}}$ transition should be dipole forbidden.

\subsection{O K-edge spectra of gibbsite}

Oxygen environments are significantly more complicated due to their involvement with a range of possible hydrogen bonding interactions. Such coordination differences are highlighted in Fig. 8 for several representative, but not exhaustive, examples. Simulated spectra were generated assuming a broadening

Table 2 Assignments in the Al K-edge spectra of gibbsite derived on comparison with corundum

\begin{tabular}{|c|c|c|c|c|}
\hline Peak label corundum (gibbsite) & $E($ corundum)/eV & $E$ (gibbsite)/eV & Assignment & Source \\
\hline $\mathrm{p}(\mathrm{p})$ & 1566.0 & 1566 & $a_{1 g}(1 s) \rightarrow a_{1 g}(3 s-l i k e)$ & K-edge ${ }^{58}$ \\
\hline $\mathrm{A}(\mathrm{A})$ & 1568.7 & 1568.5 & $a_{1 g}(1 s) \rightarrow t_{1 u}(3 p-l i k e)$ & K-edge ${ }^{58}$ \\
\hline \multirow[t]{2}{*}{$\mathrm{B}_{1}, \mathrm{~B}_{2}(\mathrm{~B})$} & $1572.2,1573.5$ & 1571 & $\mathrm{a}_{1 \mathrm{~g}}(1 \mathrm{~s}) \rightarrow \mathrm{t}_{2 \mathrm{~g}}(3 \mathrm{~d}$-like $) /$ & K-edge ${ }^{58}$ \\
\hline & & & $a_{1 g}(1 s) \rightarrow A l^{*}(3 p)-O(2 p)$ & This work \\
\hline $\mathrm{C}(\mathrm{C})$ & 1576.3 & 1578 & Multiple scattering & K-edge ${ }^{58}$ \\
\hline $\mathrm{E}(\mathrm{D})$ & 1582.2 & $\sim 1585$ & $a_{1 g}(1 s) \rightarrow e_{g}(3 d-l i k e)$ & L-edge ${ }^{64}$ \\
\hline
\end{tabular}



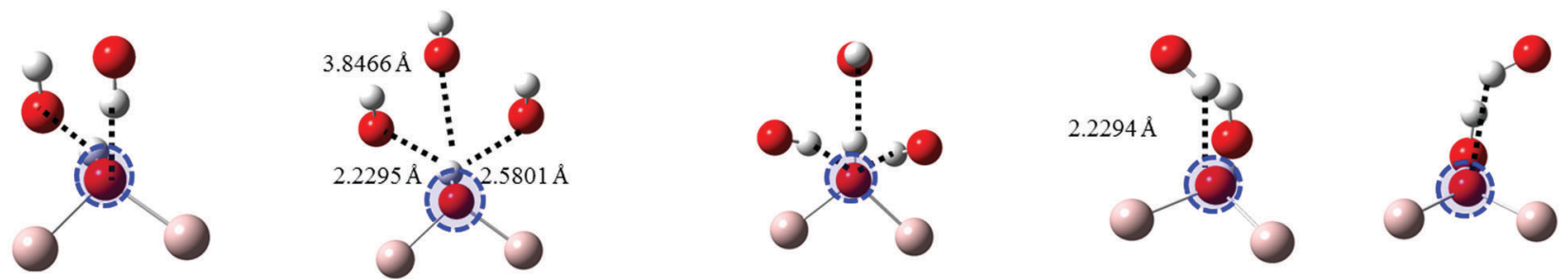

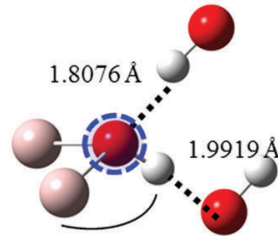

Al-O-Al-H

Dihedral $=113.6^{\circ}$

(In-plane)

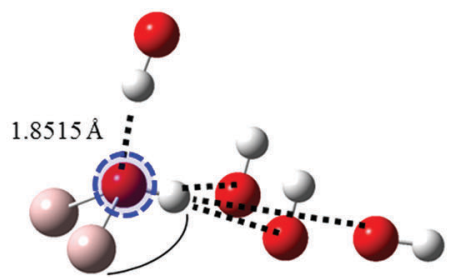

Al-O-Al-H

Dihedral $=115.9^{\circ}$

(In-plane)

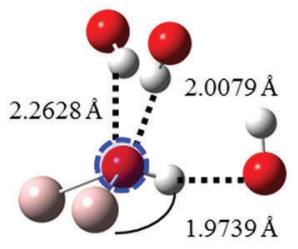

Al-O-Al-H

Dihedral $=124.1^{\circ}$

(Inter-sheet)

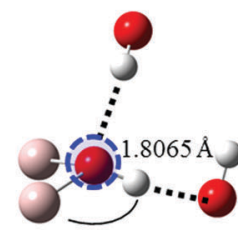

Al-O-Al-H

Dihedral $=131.7^{\circ}$

(Inter-sheet)

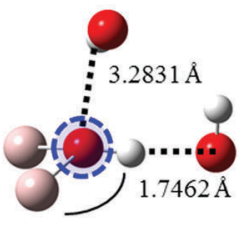

Al-O-Al-H

Dihedral $=145.7^{\circ}$

(Inter-sheet)

Fig. 8 Local geometries of the oxygen atoms used in simulations of gibbsite $\mathrm{O}$ K-edge spectra as a function of increasing (covalently bonded) $\mathrm{Al}-\mathrm{O}-\mathrm{Al}-\mathrm{H}$ dihedral angle. Excited atom is circled.

factor of $1.0 \mathrm{eV}$, and an averaged spectrum was computed from these with weightings chosen in order to best match experiment (Fig. 9). All spectra were treated with the same energy offset prior to averaging, which was chosen by aligning the peak B maximum of the averaged curve with measurement.

Regarding local structure, all oxygen atoms are threefold coordinated. The Al-O-Al-H dihedral angle for inter-sheet

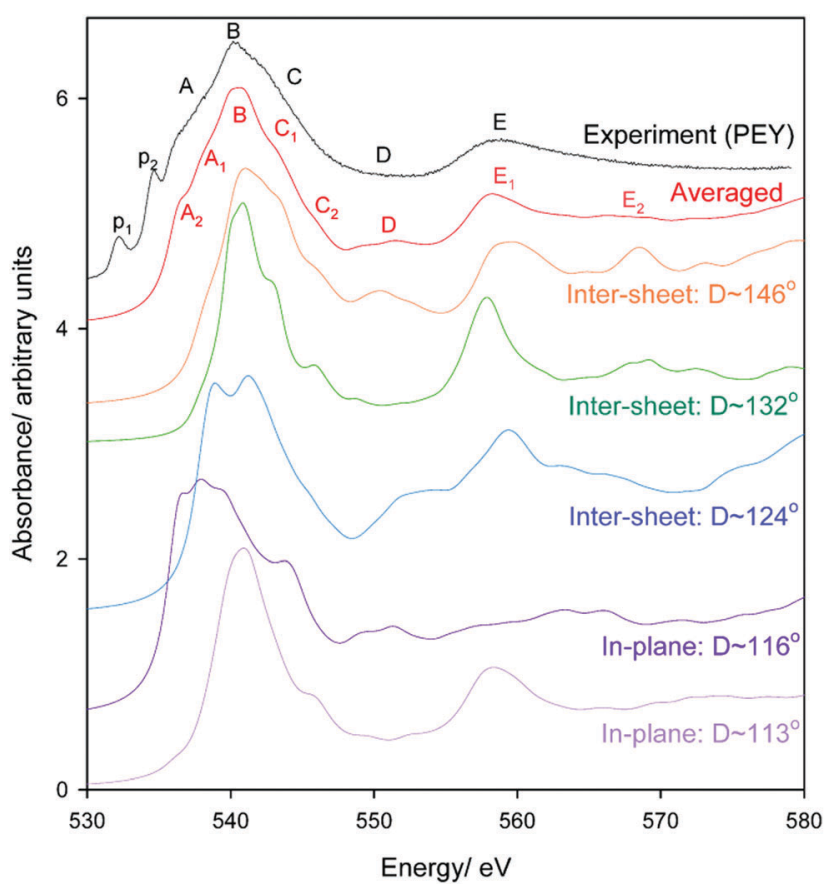

Fig. 9 Experimental and simulated $O \mathrm{~K}$-edge spectra of gibbsite as a function of $\mathrm{Al}-\mathrm{O}-\mathrm{Al}-\mathrm{H}$ dihedral angle $D$. An averaged spectrum is also provided; note the contribution of the $D \sim 116^{\circ}$ is slightly overrepresented to better match experiment as the selection in Fig. 8 is not necessarily reflective of the oxygen populations of gibbsite. interactions is found to range between $\sim 126.1-143.5^{\circ}$, generally more planar than in-plane coordination at $113.6-125.9^{\circ}$. However, the influence of dihedral angle, and consequently the change from inter-sheet to in-plane bonding, is minimal. The local geometries of oxygen with widely disparate dihedral angles of $\sim 114, \sim 132$, and $\sim 146^{\circ}$ all appear to be similar (Fig. 8), with each involved in a single H-bonding acceptor interaction with the absorbing oxygen, and one H-bonding donor interaction with its associated proton. Individual spectra (Fig. 9) for these three environments all exhibit the intense edge feature $\mathrm{B}$ at $\sim 540 \mathrm{eV}$ and transition $\mathrm{E}$ at $558 \mathrm{eV}$. Peaks C $(\sim 545 \mathrm{eV})$ and $\mathrm{E}_{2}(\sim 570 \mathrm{eV})$ may intensify somewhat with increasing dihedral angle, however this trend isn't clear cut.

The number and directionality of H-bonds are found to be significantly more influential than dihedral angle on absorption cross-section. The inter-sheet coordination environment with Al-O-Al-H dihedral $\sim 124^{\circ}$ now sees the edge feature split into two. This corresponds with geometry changes in which the absorbing oxygen now accepts two H-bonds rather than one. The new edge peak shifts to lower energy, $\sim 539 \mathrm{eV}$, thereby contributing to the broad feature A in Fig. 9 that is not described by the single acceptor/donor H-bond environments described above.

Features are perturbed significantly more in the Al-O-Al-H dihedral $D \sim 116^{\circ}$ geometry. In this case, the absorbing oxygen still accepts one $\mathrm{H}$-bond, but now the associated hydrogen participates in 2-3 donor interactions. This subtle change sees peak E $(560 \mathrm{eV})$ vanish and edge feature B split into 3-4 new peaks, all shifted to lower energy. This largely describes the measured $\mathrm{A}$ feature. In addition this H-bonding interaction also predicts a feature between $\mathrm{C}_{1}$ and $\mathrm{C}_{2}$ that helps to broaden region $\mathrm{C}$ in a manner consistent with the broad and featureless peak seen experimentally. It should be stressed that these major shifts arise from a difference in the H-bonding interactions of the proton, and not the absorbing oxygen itself. 

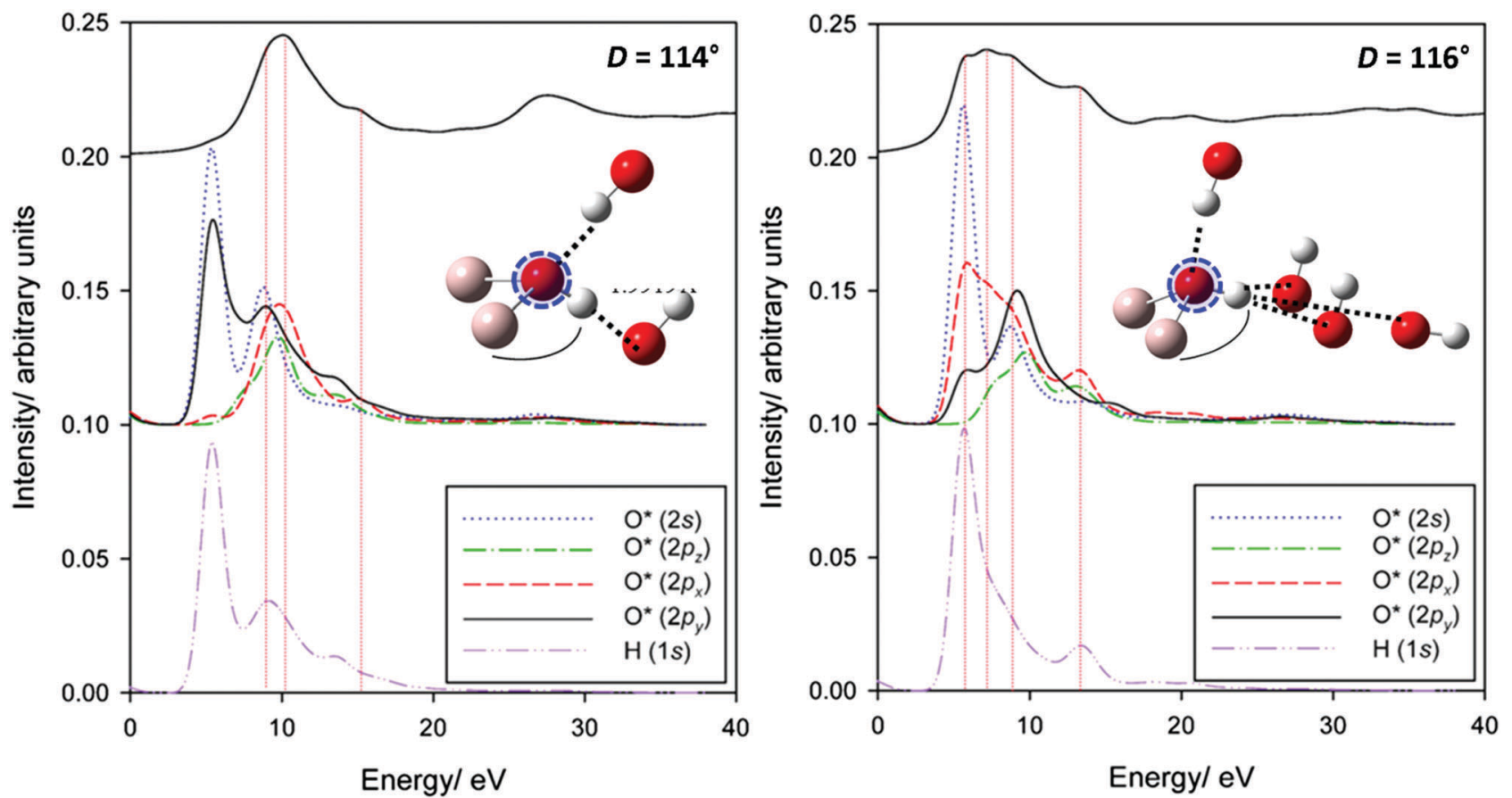

Fig. 10 Partial O K-edge spectra for centres involved in either one (left) or three (right) hydrogen bonds.

This is consistent with previous claims that oxygen is extremely sensitive to its local bonding interactions. ${ }^{72}$

To explore this splitting more deeply, partial XANES spectra in the $114^{\circ}$ and $116^{\circ}$ arrangements are explored in greater detail in Fig. 10. In the $114^{\circ}$ geometry, the single edge peak is described by transitions into $\mathrm{O} 2 \mathrm{p}$ states with some overlap with $\mathrm{O} 1 \mathrm{~s}$ and the adjacent $\mathrm{H}$ 1s states. An antibonding orbital (pointing along the [010] direction) of the $\mathrm{O} 2 \mathrm{~s} / 2 \mathrm{p}_{y}$ states with $\mathrm{H}$ $1 s$ states provides the basis for a very weakly allowed pre-edgelike transition.

Contrast this with the $116^{\circ}$ geometry system, where the $\mathrm{O}-\mathrm{H}$ bond is now directed in the [110]-direction. The $\mathrm{O} 2 \mathrm{p}_{x}$ and $\mathrm{O}$ $2 \mathrm{p}_{y}$ bands are much broader, due to the $\mathrm{H}$-bonding interactions in the $a b$-plane. The additional transitions involve these orbitals. Also important appears to be the local reduction of symmetry, relaxing selection rules. In addition to the broadening and shifting to lower energy in the low symmetry environment of the 2 -antibonding states commonly argued to dominate $\mathrm{O}$ K-edge structure, transitions into otherwise forbidden $\mathrm{O} 2$ s-dominated states are also now allowed. Finally, it is worth noting that band broadening with H-bonding interactions may be an explanation of the missing transition in O K-edge spectra of corundum (Fig. 2). That is, it is possible that a surface effect is necessary here. This may suggest surface hydrogenation. Further work is planned to explore this more deeply.

\subsection{Na K-edge spectra for gibbsitic sodium impurities}

Finally, we address sodium impurities in gibbsite. While it has been speculated that it is intercalated within the sheet-like structure of the host hydroxide, with the replacement of protons by $\mathrm{Na}^{+}$a likely candidate, ${ }^{34-36}$ to our knowledge there is no direct observation to verify this hypothesis.

In Section 3.2 we suggested that the very different coordination environments observed for inter-sheet, in-plane, and octahedral vacancy sodium should provide distinctive XANES spectra. Simulated and experimental spectra are provided in Fig. 11. The local disorder noted in the optimized structures leads to the presence of what we interpret, in the first instance, as a weak pre-edge feature in all simulated spectra. With this assignment (offset 1), simulations of both the (higher energy) inter-sheet and octahedral vacancy models demonstrate poor agreement with experiment. In the inter-sheet model, feature A largely agrees, but features $\mathrm{B}, \mathrm{C}$, and $\mathrm{D}$ are $\sim 1, \sim 3.5$, and $\sim 5 \mathrm{eV}$ lower than their corresponding measured transitions. The octahedral model shows good agreement for peaks $\mathrm{p}$ and A, however correspondences with other transitions become increasingly poor and ambiguous.

On the other hand, extremely good agreement is found in the energetically favourable in-plane conformation, with all transitions identified and exhibiting less than $\sim 0.5 \mathrm{eV}$ deviation from measured energies. Transition intensities are in fair agreement when assuming a constant line broadening parameter of $0.6 \mathrm{eV}$, with higher energy transitions more intense. This strongly supports the possibility that sodium, and potentially other monovalent impurities, can replace $\mathrm{H}^{+}$when intercalated or otherwise occluded within gibbsite.

The assumption that the lowest energy simulated transition corresponds with the measured pre-edge feature $\mathrm{p}$ at $1075.3 \mathrm{eV}$ could arguably discriminate against the other models. A second energy offset (offset 2) to instead align the most intense transition B was therefore also considered. While the edge transitions 


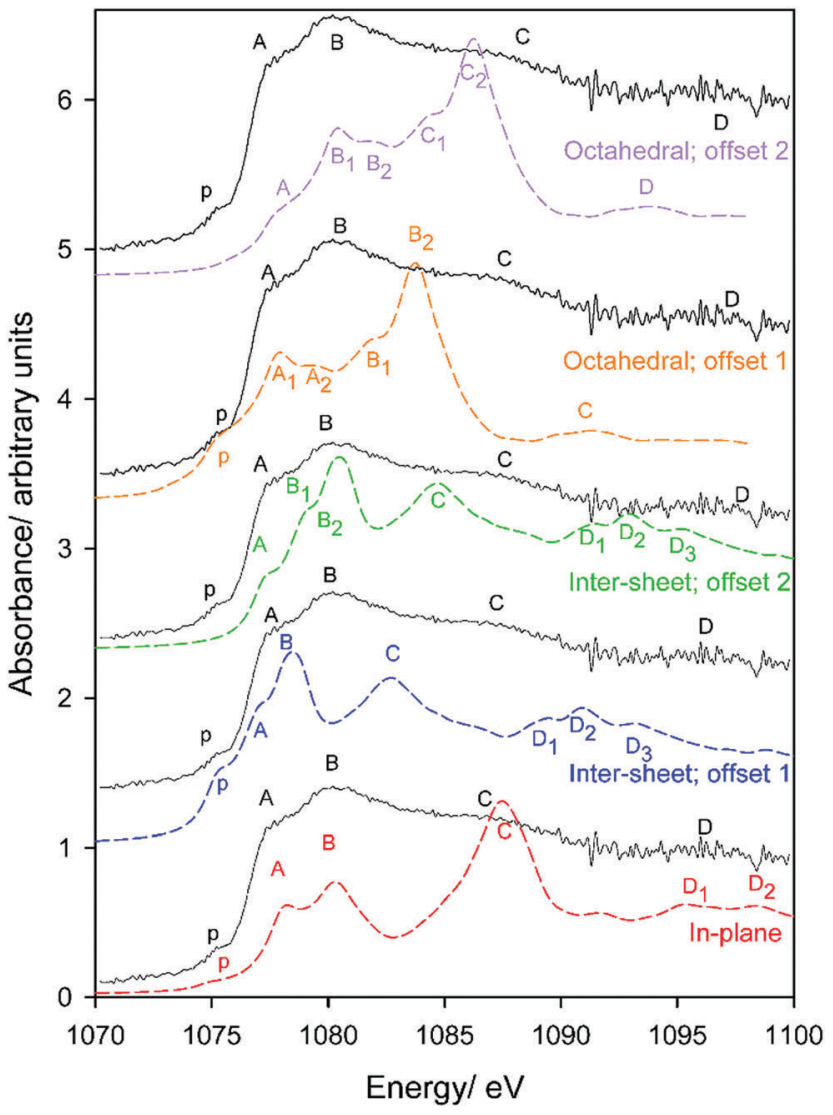

Fig. 11 Experimental and simulated $\mathrm{Na} \mathrm{K}$-edge spectra of competing models of sodium intercalation in gibbsite. Black traces are experimental PEY mode spectra, dotted traces are computed with $0.6 \mathrm{eV}$ broadening parameters, and coloured traces are computed with a non-constant broadening parameter.

now (unsurprisingly) agree reasonably well in the inter-sheet model, the pre-edge is necessarily missing and energies of transitions $\mathrm{C}$ and $\mathrm{D}$ at $\sim 1087$ and $1097 \mathrm{eV}$ experimentally are still underestimated by $\sim 2$ and $\sim 4 \mathrm{eV}$. Even in this best-case scenario, simulations are still in poor agreement with measured spectra, which suggests the relative instability of this arrangement over the in-plane intercalation mode. The octahedral model shows much closer agreement when aligning the edge maxima, but ultimately predicts unobserved features (although these are potentially obscured experimentally by line broadening), under-predicts the energies of transitions at 1087 and $1097 \mathrm{eV}$ by $\sim 1$ and $4 \mathrm{eV}$ respectively, and leaves the pre-edge unexplained. Therefore, only the in-plane geometry provides good agreement with experiment, and is indeed is also the most thermodynamically stable phase.

Finally, we make assignments for the experimental transitions Fig. 12. The in-plane intercalation model sees sodium almost recess into an octahedral vacancy and as such shows similarities with assignments for $\mathrm{Al}^{3+}$ in corundum and gibbsite as well as $\mathrm{Na}^{+}$in NaCl. The weak pre-edge again corresponds with transition into $\mathrm{Na}^{+}(3 \mathrm{~s})$ states $\left(\right.$ an $\mathrm{a}_{1 \mathrm{~g}}(1 \mathrm{~s}) \rightarrow \mathrm{a}_{1 \mathrm{~g}}(3 \mathrm{~s})$ transition). The edge transition is primarily $\mathrm{Na}^{*} 3 \mathrm{p}$ in nature, and $\mathrm{B}$ the overlap of a split $\mathrm{Na}^{*} 3 \mathrm{p}$ state and a $\mathrm{Na}^{*} 3 \mathrm{~d}$ band.

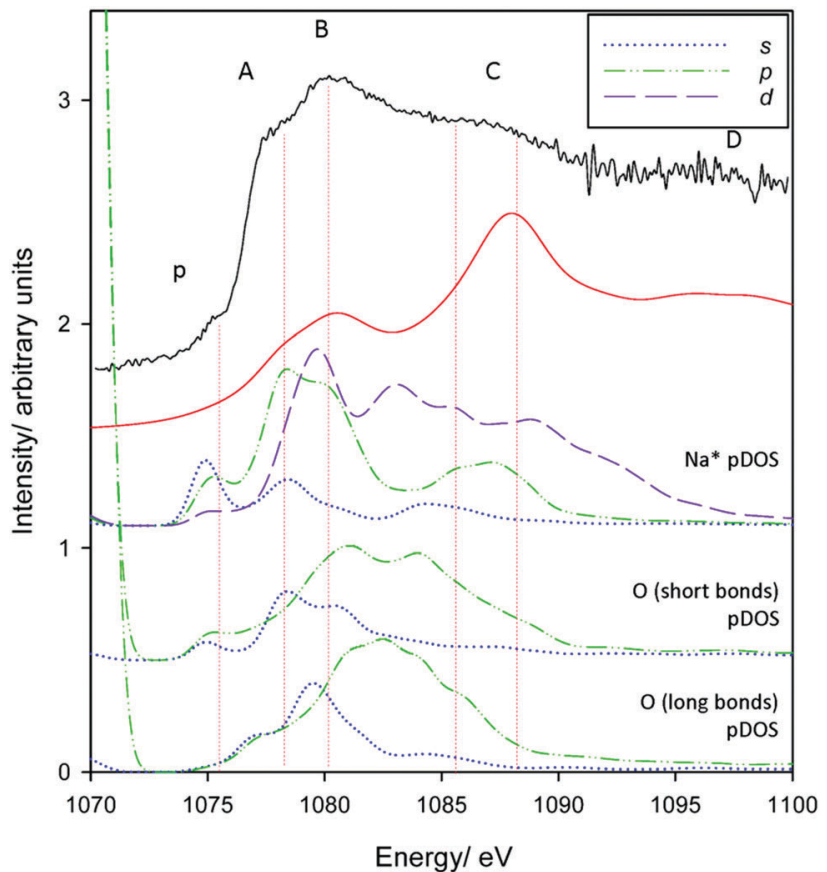

Fig. 12 pDOS calculations for $\mathrm{Na}^{*} 3 \mathrm{~s}, 3 \mathrm{p}$ and $3 \mathrm{~d}$ bands for the preferred in-plane intercalation model. Also included are the $O 2 \mathrm{~s}$ and $\mathrm{O} 2 \mathrm{p}$ bands from the short distance $\left(\sim 2.1 \AA\right.$ ) and long distance $(2.5-2.8 \AA) \mathrm{Na}^{*}-\mathrm{O}$ bond lengths (see Fig. 6 centre). A broadening parameter of $1.5 \mathrm{eV}$ is used.

Oxygen atoms in the three shorter length $\mathrm{Na}-\mathrm{O}$ interactions (Fig. 6 centre) in the highly distorted environment also appear to participate in the spectrum, whereas the longer bonds contribute to a much lesser extent. $\mathrm{O} 2 \mathrm{~s}$ contributions to peak $\mathrm{A}$ are evident, and there appear to be both $\mathrm{O} 2 \mathrm{~s}$ and $2 \mathrm{p}$ contributions to peak B. Peak C shows some coincidence with $\mathrm{Na}^{*} 3 \mathrm{p}$ and $3 \mathrm{~d}$ states with increasingly less contribution from $\mathrm{O}$ atoms, although may be purely 'multiple scattering'. Peak D does not appear to match any obvious electronic transitions, and as such is also primarily multiple scattering.

\section{Conclusions}

$\mathrm{Al}, \mathrm{O}$, and Na-K-edge XANES spectra have been analysed for Bayer gibbsite, a common precursor for many commercial alumina products. Aluminium cations are unsurprisingly found to exhibit transitions almost indistinguishable from those in corundum, consistent with observations that spectra of metallic species are dictated by local coordination (crystal field interactions). We confirm previous assignments by referencing against pDOS calculations. However, we make the additional assignment for the peak in octahedrally coordinated cation generally assigned as $\mathrm{a}_{1 \mathrm{~g}}(1 \mathrm{~s}) \rightarrow \mathrm{t}_{2 \mathrm{~g}}$ (3d-like) in K-edge spectra. This strongly overlaps with the presumably $t_{1 u}(3 p$-like) bands mixing with host (or, under a crystal field theory interpretation, ligand) $2 p$ orbitals at least in the case of oxides and chlorides. The $\mathrm{t}_{2 \mathrm{~g}}$ (3d-like) transitions, which are strictly Laporte forbidden, are allowed due to overlap with host/ligand orbitals. The corresponding $\mathrm{e}_{\mathrm{g}}(3 \mathrm{~d}$-like) transitions are too high in energy 
for significant overlap with host/ligand states and therefore transitions are much weaker.

Oxygen spectra, on the other hand, are very sensitive to immediate bonding interactions. Successful simulation from first principles for gibbsite requires averaging over representative bonding scenarios, particularly those associated with differing hydrogen bonding interactions. Subtle differences in the $\mathrm{H}$-bonding environment felt by the protons allows for $\mathrm{H}$ 1s-O 2s/O 2p mixing, broadening the $\mathrm{O}^{*}(2 \mathrm{p})$ bands responsible for the edge and allowing otherwise forbidden $\mathrm{O} 1 \mathrm{~s} \rightarrow \mathrm{O} 2 \mathrm{p}$ transitions. An unexplained feature in simulated $\mathrm{O}$ K-edge spectra of corundum could potentially arise from analogous $\mathrm{O}-\mathrm{H}$ interactions, and therefore could be explicitly due to surface chemistry, but this will have to be addressed in future works.

Finally, Na K-edge spectra have been used as a fingerprint to identify the likely coordination environment of sodium impurities. We argue that sodium effectively occupies octahedral cation vacancies within the Al-rich sheets, although lies slightly above the Al-plane as intercalation occurs by replacement of a hydrogen. This confirms prior theoretical predictions. ${ }^{36}$

\section{Conflicts of interest}

There are no conflicts to declare.

\section{Acknowledgements}

The authors gratefully acknowledge the assistance of Dr Lars Thomsen, Dr Anton Tadich, and Dr Bruce Cowie of the Australian Synchrotron for assistance in collection of XANES spectra. We also thank the New Zealand Synchrotron Group for financial support during the measurement campaign. AC thanks the University of Auckland for financial support through a UoA Doctoral Scholarship. The authors are also very grateful for the support provided by NeSI in accessing high-performance computing facilities.

\section{Notes and references}

1 C. Morterra and G. Magnacca, Catal. Today, 1996, 27, 497-532.

2 M. Trueba and S. P. Trasatti, Eur. J. Inorg. Chem., 2005, 3393-3403.

3 P. J. Chupas and C. P. Grey, J. Catal., 2004, 224, 69-79.

4 O. Boese, W. E. S. Unger, E. Kemnitz and S. L. M. Schroeder, Phys. Chem. Chem. Phys., 2002, 4, 2824-2832.

5 R. Feng, S. Liu, P. Bai, K. Qiao, Y. Wang, H. A. Al-Megren, M. J. Rood and Z. Yan, J. Phys. Chem. C, 2014, 118, 6226-6234.

6 Z. M. El-Bahy, R. Ohnishi and M. Ichikawa, Appl. Catal., B, 2003, 40, 81-91.

7 S. Jagtap, M. K. N. Yenkie, N. Labhsetwar and S. Rayalu, Microporous Mesoporous Mater., 2011, 142, 454-463.

8 A. Bhatnagar, E. Kumar and M. Sillanpää, Chem. Eng. J., 2011, 171, 811-840.
9 J. Cheng, X. Meng, C. Jing and J. Hao, J. Hazard. Mater., 2014, 278, 343-349.

10 D. Dayananda, V. R. Sarva, S. V. Prasad, J. Arunachalam and N. N. Ghosh, Chem. Eng. J., 2014, 248, 430-439.

11 C. Yang, L. Gao, Y. Wang, X. Tian and S. Komarneni, Microporous Mesoporous Mater., 2014, 197, 156-163.

12 G. J. McIntosh, G. E. K. Agbenyegah, M. M. Hyland and J. B. Metson, Langmuir, 2015, 31, 5387-5397.

13 G. J. McIntosh, G. E. K. Agbenyegah, M. M. Hyland and J. B. Metson, JOM, 2016, 68, 2463-2471.

14 G. J. McIntosh, J. B. Metson, T. Niesenhaus, T. Reek and L. M. Perander, JOM, 2014, 66, 2272-2281.

15 J. Frenzel, A. F. Oliveira, H. A. Duarte, T. Heine and G. Seifert, Z. Anorg. Allg. Chem., 2005, 631, 1267-1271.

16 A. W. P. Vermeer, J. K. McCulloch, W. H. van Riemsdijk and L. K. Koopal, Environ. Sci. Technol., 1999, 33, 3892-3897.

17 J. Rosenquist, P. Persson and S. Sjöberg, Langmuir, 2002, 18, 4598-4604.

18 F. Granados-Correa and J. Jiménez-Becerril, J. Hazard. Mater., 2009, 162, 1178-1184.

19 X. Krokidis, P. Raybaud, A.-E. Gobichon, B. Rebours, P. Euzen and H. Toulhoat, J. Phys. Chem. B, 2001, 105, 5121-5130.

20 G. J. McIntosh, J. B. Metson and M. M. Hyland, Surf. Interface Anal., 2017, 49, 1351-1358.

21 F.-S. Yen, P.-L. Cheng, H.-Y. Huang and T.-C. Lin, J. Am. Ceram. Soc., 2009, 92, 2089-2092.

22 C. Pecharromán, I. Sobrados, J. E. Iglesias, T. GonzálezCarreño and J. Sanz, J. Phys. Chem. B, 1999, 103, 6160-6170.

23 Y. Kato, K.-i. Shimizu, N. Matsushita, T. Yoshida, H. Yoshida, A. Satsuma and T. Hattori, Phys. Chem. Chem. Phys., 2001, 3, 1925-1929.

24 L. A. O'Dell, S. L. P. Savin, A. V. Chadwick and M. E. Smith, Solid State Nucl. Magn., 2007, 31, 169-173.

25 E. O. Filatova, A. S. Konashuk, F. Schaefers and V. V. Afanas'ev, J. Phys. Chem. C, 2016, 120, 8979-8985.

26 M. Digne, P. Raybaud, P. Sautet, D. Guillaume and H. Toulhoat, Phys. Chem. Chem. Phys., 2007, 9, 2577-2582.

27 K. Jirátová and L. Beránek, Appl. Catal., 1982, 2, 125-138.

28 P. Berteau, M.-A. Kellens and B. Delmon, J. Chem. Soc., Faraday Trans., 1991, 87, 1425-1431.

29 S. Srinivasan, C. R. Narayanan, A. Biaglow, R. Gorte and A. K. Datye, Appl. Catal., A, 1995, 132, 271-287.

30 G. J. McIntosh, H. Wijayaratne, G. E. K. Agbenyegah, M. M. Hyland and J. B. Metson, Light Metals. TMS The Minerals, Metals \& Materials Series, Springer International Publishing, Cham, 2018, 533-539.

31 G. J. McIntosh, H. Wijayaratne, A. Chan, L. Perander and M. Hyland, Acta Mater., 2018, 153, 226-234.

32 R. G. Haverkamp, J. B. Metson, M. M. Hyland and B. J. Welch, Surf. Interface Anal., 1992, 19, 139-144.

33 Y. Y. Park, S. O. Lee, T. Tran, S. J. Kim and M. J. Kim, Int. J. Miner. Process., 2006, 80, 126-132.

34 N. I. Eremin, M. I. Cherepanova and M. A. Maksakova, Sov. Non-Ferrous Met. Res., 1980, 8, 263-266.

35 N. I. Eremin, M. I. Cherepanova, N. S. Shmorgunenko and M. A. Maksakova, Sov. Non-Ferrous Met. Res., 1980, 8, 132-135. 
36 M.-Y. Lee, A. L. Rohl, J. D. Gale, G. M. Parkinson and F. J. Lincoln, Trans. IChemE Part A, 1996, 74, 739-743.

37 A. V. Besserguenev, A. M. Fogg, R. J. Francis, S. J. Price, D. O'Hare, V. P. Isupov and B. P. Tolochko, Chem. Mater., 1997, 9, 241-247.

38 S.-L. Wang, C.-Y. Cheng, Y.-M. Tzou, R.-B. Liaw, T.-W. Chang and J.-H. Chen, J. Hazard. Mater., 2007, 147, 205-212.

39 B. C. C. Cowie, A. Tadich and L. Thomsen, AIP Conf. Proc., 2010, 1234, 307-310.

40 E. Gann, C. R. McNeill, A. Tadich, B. C. C. Cowie and L. Thomsen, J. Synchrotron Radiat., 2016, 23, 374-380.

41 M. Taillefumier, D. Cabaret, A.-M. Flank and F. Mauri, Phys. Rev. B: Condens. Matter Mater. Phys., 2002, 66, 195107.

42 C. Gougoussis, M. Calandra, A. P. Seitsonen and F. Mauri, Phys. Rev. B: Condens. Matter Mater. Phys., 2009, 80, 075102.

43 P. E. Blöchl, Phys. Rev. B: Condens. Matter Mater. Phys., 1994, 50, 17953-17979.

44 D. Vanderbilt, Phys. Rev. B: Condens. Matter Mater. Phys., 1990, 41, 7892-7895.

45 R. Haydock, V. Heine and M. J. Kelly, J. Phys. C, 1975, 8, 2591.

46 J. J. Rehr and A. L. Ankudinov, Coord. Chem. Rev., 2005, 249, 131-140.

47 C. Wei, Z. Feng, G. G. Scherer, J. Barber, Y. Shao-Horn and Z. J. Xu, Adv. Mater., 2017, 29, 1606800.

48 V. Bilovol, A. V. Gil Rebaza, A. M. Mudarra Navarro, L. Errico, M. Fontana and B. Arcondo, Appl. Surf. Sci., 2017, 425, 1066-1073.

49 A. K. Sinha, M. N. Singh, S. N. Achary, A. Sagdeo, D. K. Shukla and D. M. Phase, J. Magn. Magn. Mater., 2017, 435, 87-95.

50 G. Della Ventura, F. Galdenzi, G. Cibin, R. Oberti, W. Xu, S. Macis and A. Marcelli, Phys. Chem. Chem. Phys., 2018, 20, 21764-21771.

51 J. P. Perdew, K. Burke and M. Ernzerhof, Phys. Rev. Lett., 1996, 77, 3865-3868.

52 P. Giannozzi, O. Andreussi, T. Brumme, O. Bunau, M. B. Nardelli, M. Calandra, R. Car, C. Cavazzoni, D. Ceresoli, M. Cococcioni, N. Colonna, I. Carnimeo, A. D. Corso, S. D. Gironcoli, P. Delugas, J. R. A. DiStasio, A. Ferretti, A. Floris, G. Fratesi, G. Fugallo, R. Gebauer, U. Gerstmann, F. Giustino, T. Gorni, J. Jia, M. Kawamura, H. Y. Ko, A. Kokalj, E. Küçükbenli, M. Lazzeri, M. Marsili, N. Marzari, F. Mauri, N. L. Nguyen, H. V. Nguyen, A. Oterode-la-Roza, L. Paulatto, S. Poncé, D. Rocca, R. Sabatini, B. Santra, M. Schlipf, A. P. Seitsonen, A. Smogunov, I. Timrov, T. Thonhauser, P. Umari, N. Vast, X. Wu and S. Baroni, J. Phys.: Condens. Matter, 2017, 29, 465901.
53 G. Paolo, B. Stefano, B. Nicola, C. Matteo, C. Roberto, C. Carlo, C. Davide, L. C. Guido, C. Matteo, D. Ismaila, C. Andrea Dal, G. Stefano de, F. Stefano, F. Guido, G. Ralph, G. Uwe, G. Christos, K. Anton, L. Michele, M.-S. Layla, M. Nicola, M. Francesco, M. Riccardo, P. Stefano, P. Alfredo, P. Lorenzo, S. Carlo, S. Sandro, S. Gabriele, P. S. Ari, S. Alexander, U. Paolo and M. W. Renata, J. Phys.: Condens. Matter, 2009, 21, 395502.

54 D. Cabaret, P. Sainctavit, P. Ildefonse and A.-M. Flank, J. Phys.: Condens. Matter, 1996, 8, 3691-3704.

55 R. Nemausat, B. Ch, G. Ch and D. Cabaret, J. Phys.: Conf. Ser., 2016, 712, 012006.

56 D. Cabaret, E. Gaudry, M. Taillefumier, P. Sainctavit and F. Mauri, Phys. Scr., 2005, 131.

57 D. Cabaret and C. Brouder, J. Phys.: Conf. Ser., 2009, 190, 012003.

58 D. Li, G. M. Bancroft, M. E. Fleet, X. H. Feng and Y. Pan, Am. Mineral., 1995, 80, 432-440.

59 P. Ildefonse, D. Cabaret, P. Sainctavit, G. Calas, A.-M. Flank and P. Lagarde, Phys. Chem. Miner., 1998, 25, 112-121.

60 A. Mottana, T. Murata, A. Marcelli, G. Della Ventura, G. Cibin, Z. Wu and R. Tessadri, J. Appl. Crystallogr., 1998, 31, 890-898.

61 J. L. Dehmer, J. Chem. Phys., 1972, 56, 4496-4504.

62 C. Weigel, G. Calas, L. Cormier, L. Galoisy and G. S. Henderson, J. Phys.: Condens. Matter, 2008, 20, 135219.

63 J. A. V. Bokhoven, T. Nabi, H. Sambe, D. E. Ramaker and D. C. Koningsberger, J. Phys.: Condens. Matter, 2001, 13, 10247.

64 E. O. Filatova and A. S. Konashuk, J. Phys. Chem. C, 2015, 119, 20755-20761.

65 E. O. Filatova, A. S. Konashuk, S. S. Sakhonenkov, A. A. Sokolov and V. V. Afanas'ev, Sci. Rep., 2017, 7, 4541.

66 H. Y. Huang, R. T. Yang, D. Chinn and C. L. Munson, Ind. Eng. Chem. Res., 2003, 42, 2427.

67 G. S. Henderson, D. R. Neuville and L. Cormier, Chem. Geol., 2009, 259, 54-62.

68 R. Gunnella, M. Benfatto, A. Marcelli and C. R. Natoli, Solid State Commun., 1990, 76, 109-111.

69 R. J. Prado and A. M. Flank, Phys. Scr., 2005, 165.

70 K. Momma and F. Izumi, J. Appl. Crystallogr., 2011, 44, 1272-1276.

71 H. Saalfeld and M. Wedde, Z. Kristallogr., 1974, 139, 129-135.

72 Y. F. Hu, R. K. Xu, J. J. Dynes, R. I. R. Blyth, G. Yu, L. M. Kozak and P. M. Huang, Geochim. Cosmochim. Acta, 2008, 72, 1959-1969. 